\title{
Nitrate induced coronary vasodilatation: differential effects of sublingual application by capsule or spray
}

\author{
M Pfister, C Seiler, M Fleisch, H Göbel, T Lüscher, B Meier
}

\begin{abstract}
Background-Sublingual nitroglycerin (glyceryltrinitrate, GTN) capsules or isosorbide dinitrate (ISDN) spray are routinely used to treat anginal attacks and to vasodilate maximally the epicardial coronary arteries during coronary angiography.

Objective-To compare the coronary vasodilatory effects of GTN capsules and ISDN spray with those induced by intracoronary GTN using quantitative coronary angiography.

Design-96 patients $(79$ men and 17 women; median age 59 years) were randomised to four groups to receive either a sublingual capsule containing $0.8 \mathrm{mg} \mathrm{GTN}$ or two puffs of spray delivering $0.8 \mathrm{mg}$ ISDN, followed or preceded by an intracoronary bolus of $0.2 \mathrm{mg}$ GTN used as reference for maximal vasodilatation.

Results-There was a significant increase in the mean diameter of coronary arteries in angiographically normal segments in patients who received either intracoronary GTN (groups 1 and 2) or ISDN spray (group 4) as a first application (group 1, $0.46 \mathrm{~mm},+17 \%$, (baseline vessel diameter $100 \%$ ), p $<0.001$; group $2,0.45 \mathrm{~mm},+13 \%$, p $<0.001$; group $4,0.47 \mathrm{~mm},+13 \%$, p < 0.05). Patients who received a sublingual GTN capsule as the first application mode (group 3 ) had no significant change in epicardial vessel diameter $(0.10 \mathrm{~mm}$, $+5 \%, p=0.3$ ).
\end{abstract}

Conclusions-Sublingual ISDN spray may be more efficacious than sublingual GTN capsules in certain patients with anginal attacks. ISDN spray should be preferred over capsules in coronary angiographic procedures.

(Heart 1998;80:365-369)

Keywords: angiography; isosorbide dinitrate; nitroglycerin; vasodilatation; angina

Division of Cardiology, University Hospital, 3010 Berne, Switzerland M Pfister

C Seiler

M Fleisch

H Göbel

T Lüscher

B Meier

Correspondence to: Dr Seiler.

Accepted for publication 9 February 1998

Organic nitrates are potent vasodilators that are often used therapeutically to treat cardiovascular disease. ${ }^{1}$ The biochemical basis of their pharmacological action is the release of nitric oxide from the nitrate group, which activates enzyme soluble guanylate cyclase, leading to the accumulation of cyclic guanosine monophosphate and subsequent vascular relaxation. $^{2}{ }^{3}$ Through this mechanism, organic nitrates exert a wide spectrum of physiological actions by dilating peripheral and regional arterial and venous smooth muscle coronary blood vessels, thus increasing coronary blood flow. These effects lead to a decrease in myocardial oxygen demand and preload as well as an increase in oxygen supply, producing symptomatic relief in angina pectoris and congestive heart failure. ${ }^{45}$ Aside from the biochemical and physiological effects that are common to all nitrates, individual nitrates differ substantially in their pharmacological potency and pharmacokinetics. ${ }^{6}$ Experimental work has shown different sensitivity to nitrates in various vessel sections. ${ }^{78}$

Sublingual nitroglycerin (glyceryltrinitrate, GTN) capsules or isosorbide dinitrate (ISDN) spray are routinely used to treat anginal attacks and to maximally vasodilate the epicardial coronary arteries during coronary angiography. Alternatively, GTN can be given by the intracoronary route. The safety and efficacy of these modes of treatment are well established, ${ }^{79}$ but a controlled comparative study of the effect of these different methods of application on coronary artery calibre has not been reported.

This study aimed to investigate the coronary vasodilatory effects of different nitrate preparations using quantitative coronary angiography. Sublingual GTN capsules and ISDN spray were compared with intracoronary GTN.

\section{Methods}

Ninety six patients (79 men and 17 women; median (range) age 59 (35-77) years) were studied (table 1).

\section{PATIENT SELECTION}

Patients undergoing diagnostic coronary angiography without contraindication to nitrates were eligible. Patients were excluded if they: had received treatment with nitrates or calcium antagonists, or both, less than 24 hours before cardiac catheterisation; were intolerant to nitrates; or had systemic hypotension, acute/ unstable coronary syndromes (unstable angina or ongoing myocardial infarction), valvar aortic stenosis, or hypertrophic obstructive cardiomyopathy and/or renal dysfunction.

\section{CORONARY ANGIOGRAPHY}

The same non-ionic contrast media was used (Iopamidol; Bracco, Milan, Italy) in all patients. Multiple views of the left coronary artery were obtained and the best right anterior oblique projection was chosen to minimise overlap of proximal left coronary artery branches. 
Table 1 Clinical data

\begin{tabular}{lllll}
\hline & $\begin{array}{l}\text { Group 1 } \\
(\text { ic/spray }) \\
(n=26)\end{array}$ & $\begin{array}{l}\text { Group 2 } \\
(\text { ic/caps) } \\
(n=21)\end{array}$ & $\begin{array}{l}\text { Group 3 } \\
(\text { caps/ic) } \\
(n=27)\end{array}$ & $\begin{array}{l}\text { Group 4 } \\
(\text { spray/ic) } \\
(n=22)\end{array}$ \\
\hline $\begin{array}{l}\text { Mean (SD) age (years) } \\
\text { Sex (F/M) }\end{array}$ & $57(2.1)$ & $56(2.3)$ & $57(2.1)$ & $59(2.3)$ \\
Coronary artery disease & $7 / 19$ & $3 / 18$ & $2 / 25$ & $5 / 17$ \\
\hline
\end{tabular}

$\mathrm{p}$ values not significant for all parameters.

ic, intracoronary nitroglycerin; spray, isosorbide dinitrate spray; caps, sublingual glyceryltrinitrate capsule.
Table 2 Changes in diameter of proximal non-diseased coronary artery segments after application of different nitrate formulations

\begin{tabular}{llll}
\hline & \multicolumn{3}{c}{ Mean (SD) artery diameter $(\mathrm{mm})$} \\
\cline { 2 - 4 } & Baseline & After step 1 & After step 2 \\
\hline Group 1 (ic/spray) & $3.2(1.0)$ & $3.6(0.9)^{\star}$ & $3.7(1.1)$ \\
Group 2 (ic/caps) & $3.5(1.0)$ & $3.9(1.3)^{\star}$ & $4.0(1.3)$ \\
Group 3 (caps/ic) & $3.0(1.0)$ & $3.1(0.9)$ & $3.7(1.0) \dagger$ \\
Group 4 (spray/ic) & $3.4(1.0)$ & $3.8(1.1)^{\star}$ & $3.9(1.2)$
\end{tabular}

${ }^{\star} \mathrm{p}<0.05$ artery diameter after step $1 v$ baseline artery diameter. $\mathrm{tp}<0.05$ artery diameter after step $2 v$ artery diameter after step 1.

ic, intracoronary nitroglycerin; spray, isosorbide dinitrate spray; caps, sublingual glyceryltrinitrate capsule.

Lumen diameter was measured using an electronic quantitative coronary measurement system (DCI) in the catheterisation laboratory provided by the $x$ ray equipment (Philips DA Best, the Netherlands). Measurements of relative and absolute lumen diameter were made in a proximal, angiographically non-diseased coronary artery segment. Measurements were repeated at the same site after nitrate administration, care being taken not to move the table or the patient.
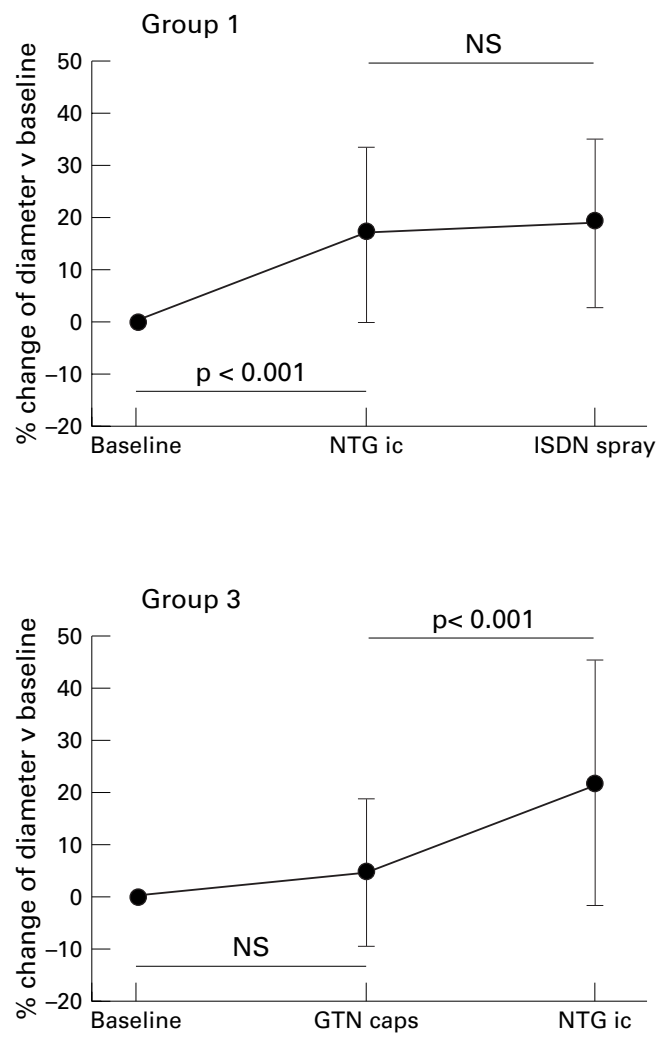

Systolic and diastolic aortic blood pressure and heart rate were recorded. Right heart catheterisation was performed in 31 of 96 patients to measure pulmonary capillary wedge pressure (PCWP) before and after each application of nitrates.

STUDY GROUPS

Patients were randomised to receive either a sublingual capsule containing $0.8 \mathrm{mg}$ GTN or two puffs of spray delivering $0.4 \mathrm{mg}$ ISDN per puff, followed or preceded by an intracoronary bolus of $0.2 \mathrm{mg}$ GTN used as reference for maximal vasodilatation. Twenty six patients received intracoronary GTN/ISDN spray (group 1), 21 intracoronary GTN/GTN capsule (group 2), 27 GTN capsule/intracoronary GTN (group 3), and 22 ISDN spray/ intracoronary GTN (group 4).

BASELINE

Baseline was defined to select the maximal and minimal baseline vessel diameter of a normal appearing proximal segment of the left coronary artery.

\section{NITRATE ADMINISTRATION}

Patients received sublingual GTN capsules, sublingual ISDN spray, or intracoronary GTN after baseline angiography. A selective coronary angiogram with unchanged angulation and focus to image intensifier distance was repeated three minutes after nitrate administration. The same procedure was performed five minutes after application of the second nitrate preparation.
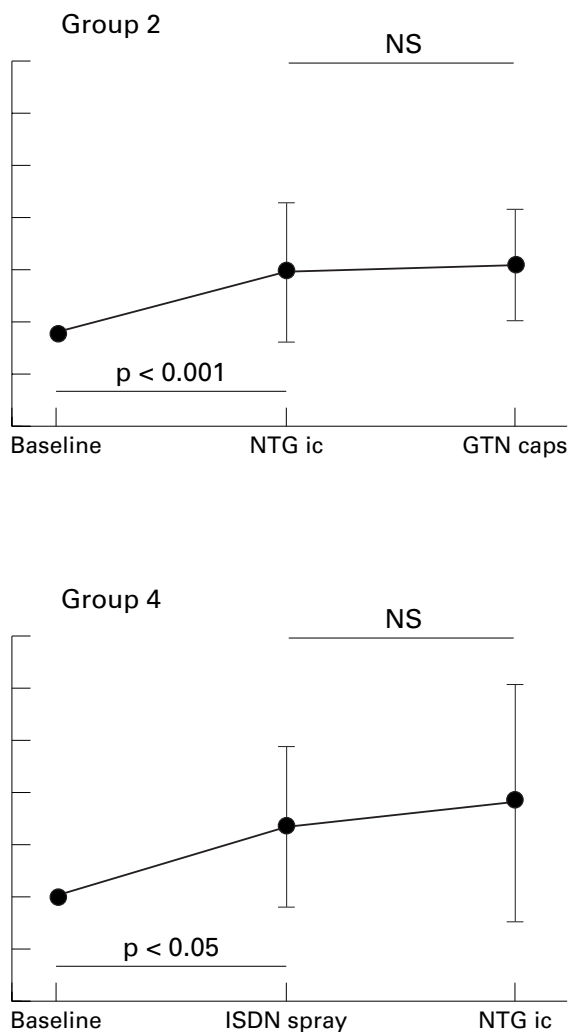

Figure 1 Changes in vessel diameter (\% change of baseline vessel diameter) of angiographically normal proximal coronary artery segments after application of different nitrate formulations. NTG ic, intracoronary bolus of $0.2 \mathrm{mg}$ glyceryltrinitrate; ISDN, two puffs of a spray delivering $0.4 \mathrm{mg}$ isosorbide dinitrate; GTN caps, glyceryltrinitrate capsules. 

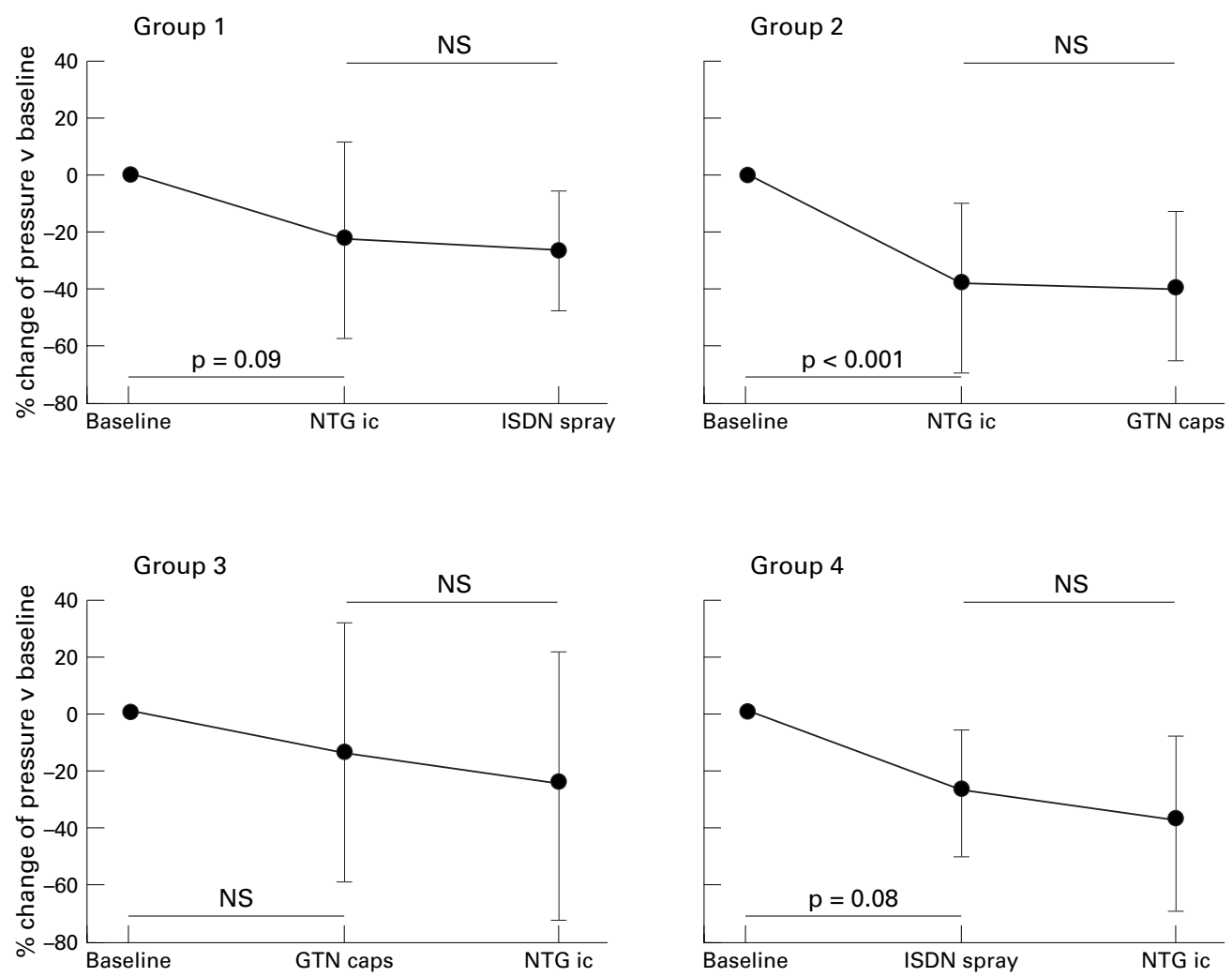

Figure 2 Changes in pulmonary capillary wedge pressure (\% change of baseline pressure) during right heart catheterisation after different modes of nitrate administration. NTG ic, intracoronary bolus of 0.2 mg glyceryltrinitrate; ISDN, two puffs of a spray delivering $0.4 \mathrm{mg}$ isosorbide dinitrate; GTN caps, glyceryltrinitrate capsules.

CALCULATIONS AND STATISTICAL ANALYSIS Absolute coronary artery diameters $(\mathrm{mm})$ were measured. Calibration was done using a diagnostic $5 \mathrm{~F}$ catheter. Vessel diameter and PCWP were measured at baseline and three minutes after administration of each preparation.

Means (SD) were calculated for measurements from baseline and nitrate angiograms and PCWP values. Statistical difference among different protocol steps were evaluated using analysis of variance (ANOVA) for repeated measures. Analysis of variance was applied for comparison between groups. A p value of 0.05 was considered significant. SYSTAT 6.01 statistics software program (Evanston, California, USA) was used to analyse the data.

\section{Results}

Changes in the coronary artery diameter of 96 patients were studied by quantitative angiography. Eighty two patients had pronounced coronary artery disease (one or more coronary artery stenoses greater than $50 \%$ in diameter).

There was a significant increase in the mean diameter of coronary arteries in patients who received either intracoronary GTN capsules or sublingual ISDN spray as the first application mode (fig 1). The mean increase in vessel diameter was $0.46 \mathrm{~mm}(+17 \%$; baseline vessel diameter $100 \%$ ) in group $1,0.45 \mathrm{~mm}$ $(+13 \%)$ in group 2 , and $0.47 \mathrm{~mm}(+13 \%)$ in group 4. Patients who received sublingual GTN capsules as the first application mode showed no significant change in vessel diam- eter $(0.10 \mathrm{~mm}(+5 \%), \mathrm{p}=0.3 v$ baseline (table 2 and fig 1 ).

A mean (SD) decrease in PCWP was seen in patients who received intracoronary GTN administration as the first application mode (6.3 (2.1) $\mathrm{mm} \mathrm{Hg}(-26 \%)$ in group 1 and 8.9 (2.3) $\mathrm{mm} \mathrm{Hg}(-40 \%)$ in group 2). Wedge pressure also declined in group 4 patients who received ISDN spray as the first application mode $(7.0(1.7) \mathrm{mm} \mathrm{Hg}(-40 \%))$ and in those of group 3 who were given a sublingual GTN capsule (3.4 (1.8) $\mathrm{mm} \mathrm{Hg} \mathrm{(-23 \% ))} \mathrm{(fig} \mathrm{2).}$

There were no significant changes in heart rate. Intracoronary GTN caused a conspicuous decrease in systolic aortic blood pressure (mean (SD) -13.3 (3.1) $\mathrm{mm} \mathrm{Hg}(-11 \%)$ in group 1 and -17.5 (3.4) $\mathrm{mm} \mathrm{Hg}(-13 \%)$ in group 2) (table 3). The decrease in systolic pressure after ISDN spray as the first application mode (group 4) was less than in groups 1 and 2 but not statistically different from that after sublingual GTN capsule (group 3) (-7.1 (3.4) $\mathrm{mm} \mathrm{Hg}(-5 \%)$ in group 4 compared with -11.1 (3.6) $\mathrm{mm} \mathrm{Hg}(-7 \%)$ in group 3). The decreases in diastolic aortic pressure after the first nitrate application were not significant (table 3).

\section{Discussion}

The present study shows that the vasodilatory effects of nitrates in angiographically normal coronary artery segments of patients with coronary disease differ, depending on the route and form of application and on different vascular beds. Administration of two GTN 
Table 3 Changes in systolic and diastolic aortic blood pressure after application of different nitrate formulations

\begin{tabular}{llll}
\hline & \multicolumn{3}{l}{ Mean (SD) blood pressure ( $m m ~ H g)$} \\
\cline { 2 - 4 } & Baseline & After step 1 & After step 2 \\
\hline Group 1 (ic/spray) & & & \\
$\quad$ Systolic & $116(5.4)$ & $102(4.2)$ & $100(4.5)$ \\
$\quad$ Diastolic & $74(2.6)$ & $72(2.5)$ & $70(2.6)$ \\
Group 2 (ic/caps) & & & \\
$\quad$ Systolic & $129(5.8)$ & $111(4.5)$ & $114(4.9)$ \\
$\quad$ Diastolic & $76(2.8)$ & $76(2.7)$ & $75(2.9)$ \\
Group 3 (caps/ic) & & $123(4.5)$ & $109(4.9)$ \\
$\quad$ Systolic & $130(5.8)$ & $12(2.7)$ & $74(2.9)$ \\
$\quad$ Diastolic & $79(2.8)$ & $79(2.7)$ & $109(5.2)$ \\
Group 4 (spray/ic) & $132(6.2)$ & $121(4.8)$ & $71(3.0)$ \\
$\quad$ Systolic & $74(3.0)$ & $75(2.9)$ & \\
$\quad$ Diastolic & &
\end{tabular}

ic, intracoronary nitroglycerin; spray, isosorbide dinitrate spray; caps, sublingual glyceryltrinitrate capsule.

capsules caused only a slight increase in PCWP, which was not statistically significant compared with increases seen after treatment with other nitrate formulations. While a conspicuous decrease in systolic aortic blood pressure was observed in the four study groups, only intracoronary GTN and ISDN spray led to a comparable and significant increase in coronary artery diameter. There was no significant further effect after application of the second nitrate preparation in patients who received ISDN spray or intracoronary GTN as the first application mode, while significant vasodilatation was induced in patients given intracoronary nitrate after application of sublingual GTN as a first application mode.

Our findings suggest that different nitrate preparations induce different short term maximal coronary vasodilatation in the cardiac catheterisation laboratory. These differences may relate to different bioavailability, pharmacokinetics, and/or drug potency, although differences in in vitro potency seem larger than corresponding in vivo activities. ${ }^{2}$

Different doses are unlikely to explain the differential effects observed after administration of sublingual GTN capsules compared with those after application of ISDN spray. Nitric oxide released from the nitrate group is responsible for the mechanism of action of nitrates. Dinitrates can release two nitric oxide molecules, while mononitrates release only one molecule. As GTN is most commonly metabolised to dinitrates, ISDN and GTN most likely yield a similar concentration of nitric oxide. The spray and capsules used in the present study delivered $0.8 \mathrm{mg}$ of active substance to the patient, indicating that dosage differences did not lead to bias in the results.

Differences in pharmacokinetics may be important. Enoral absorption of inhaled ISDN may be more rapid than absorption of a sublingual GTN capsule. There are different systemic metabolic rates for intracoronary GTN and ISDN ${ }^{6}$ : half lives of the two organic nitrate preparations administered intravenously are three and 10 minutes, respectively. Systemic clearance of GTN is affected by cardiac output. ${ }^{6}$ Moreover, pronounced arteriovenous extraction of GTN is related partly to vascular (intracoronary) metabolism. Hence, local intra- coronary clearance of GTN may be increased compared with that of ISDN.

Furthermore, in contrast to formulations of ISDN, GTN capsules have to be metabolised to active metabolites. Therefore, sublingual GTN may possibly exert a more pronounced effect later; however, the observation period used here was at least three minutes and in an earlier study peak plasma concentrations were detected at one and a half minutes following administration of intravenous ISDN, five minutes following inhaled ISDN, and three minutes following sublingual GTN. ${ }^{10}$

The present study has important clinical implications. Intracoronary injection of GTN after application of ISDN spray seems to yield no additional benefit in terms of vasodilatation of epicardial coronary artery segments. Our findings also indicate that the anti-ischaemic effect of sublingual GTN capsules is primarily related to a conspicuous decrease in systolic aortic blood pressure (reduction of afterload) and possibly to dilatation of the systemic venous system (reduction of preload) but not very much dilatation of the coronary arteries.

In previous studies inhaled ISDN produced qualitatively similar but more rapid and sustained haemodynamic responses than those of sublingual GTN, indicating superior relief from angina with ISDN. ${ }^{10}{ }^{11}$ In another study the clinical and circulatory effects of ISDN were similar compared with those of GTN. $^{12}$

The present study is the first to document an absent vasodilatory response of the coronary artery system following administration of sublingual GTN compared with that following inhaled ISDN, a finding which possibly suggests that ISDN spray is more efficacious than sublingual GTN capsules in certain patients with anginal attacks. Clearly, ISDN spray is the preferred mode of administration at coronary angiography.

CONCLUSIONS

Coronary artery disease affects the response of non-diseased proximal coronary segments to nitrate. Nitrate administration by ISDN spray or intracoronary GTN increases equally the diameter of angiographically normal proximal coronary artery segments in patients with coronary artery disease, whereas administration of two GTN capsules had no vasodilatory effect on the epicardial coronary artery system.

We therefore recommend routine administration of sublingual ISDN spray in coronary angiographic procedures. Further studies are required to evaluate whether the different efficacy of ISDN spray may be decisive in the treatment of acute anginal attacks.

\footnotetext{
1 Abrams J. The role of nitrates in coronary heart disease. Arch Intern Med 1995;155:357-64.

2 Fung HL. Do nitrates differ? Br f Clin Pharmacol 1992;34: 5-9S.

3 Murad F. Cyclic guanosine monophosphate as a mediator of vasodilation. F Clin Invest 1986;78:1-5.

4 Thadani U. Role of nitrates in angina pectoris. Am $\mathcal{f}$ Cardiol 1992;70:43-53B.

5 Abrams J. Mechanisms of action of the organic nitrates in the treatment of myocardial ischemia. Am $\mathcal{f}$ Cardiol 1992;70:30-42B.
} 
6 Fung HL. Pharmacokinetics and pharmacodynamics of organic nitrates. Am f Cardiol 1987;60:4-9H.

Bassenge E, Zanzinger J. Nitrates in different vascular beds, nitrate tolerance and interactions with endothelial function. Am f Cardiol 1992;70:23-9B.

8 Lüscher TF. Endogenous and exogenous nitrates and their role in myocardial ischemia. Br F Clin Pharmacol 1992;34 (suppl 1):29-35S.

9 Feldman RL, Marx JD, Pepine CJ, et al. Analysis of coronary responses to various doses of intracoronary nitroglycerin. Circulation 1982;66:321.
10 Culling W. Haemodynamics and plasma concentrations following sublingual GTN and intravenous, or inhaled, isosorbide dinitrate. Br f Clin Pharmacol 1984;17:125131.

11 Marmor A. Comparative evaluation of a new formulation of isosorbide dinitrate oral spray and sublingual nitroglycerin tablets. Am 7 Cardiol 1990;65:43-5J.

12 Goldstein RE, Rosing DR, Redwood DR, et al. Clinical and circulatory effects of isosorbide dinitrate. Comparison with nitroglycerin. Circulation 1971;18:629-40.

\section{IMAGES IN CARDIOLOGY}

\section{Fibrosarcoma of the heart}

A 43 year old man presented with severe congestive cardiac failure. The posteroanterior chest $x$ ray shows extreme enlargement of the cardiac silhouette and a particularly prominent bulge in the left upper border. The magnetic resonance imaging in the coronal plane shows that the heart, the thoracic aorta, and the pulmonary arteries were all encased by an extremely thick mass of tissue. The patient underwent sternotomy and complete resection of the tumour, which was found to have encased the heart and the great vessels. The central venous pressure during operation was $22 \mathrm{~mm} \mathrm{Hg}$ and $9 \mathrm{~mm} \mathrm{Hg}$ before and after tumour resection, respectively, suggesting that there may have been some restriction in the haemodynamics. Haematoxylin and eosin stained sections showed that the tumour was composed of fascicles of moderately atypical cells with low mitotic activity. These cells were immunopositive for vimentin but negative for various epithelial, mesothelial, endothelial, muscle, and nerve sheath markers. The tumour was diagnosed as a fibrosarcoma.

The patient recovered very well after the operation; however, four months later he presented with abdominal masses. At laparotomy, large retrohepatic masses were noted and these were considered to be unresectable. Histological examination of the biopsy specimens taken from these masses showed similar findings to those taken from the cardiac tumour. The patient was given chemotherapy and other palliative forms of treatment.

YEAN T LIM CHUEN-NENG LEE BOON-LOCK CHIA

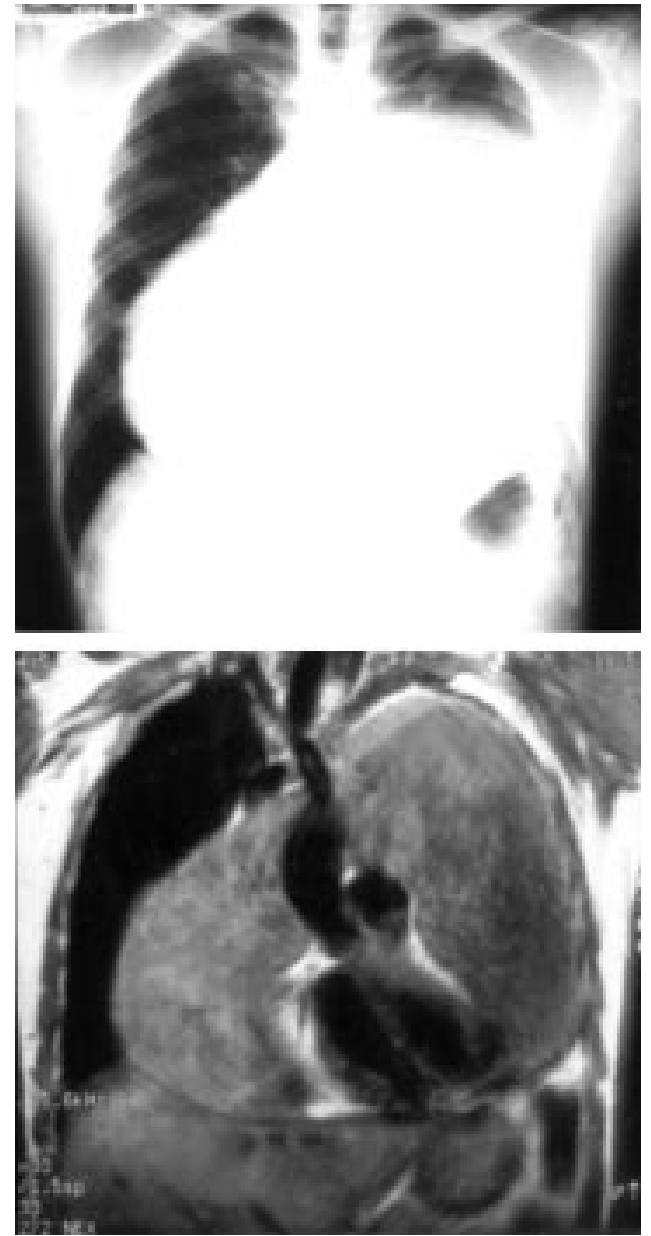

